\title{
Modificaciones a la política editorial de la Revista Biomédica.
}

\section{Editorial}

Renán A. Góngora-Biachi.

Editor, Revista Biomédica, Universidad Autónoma de Yucatán, Mérida, Yucatán, México.

Con la edición del presente número, la Revista Biomédica inicia el $14^{\circ}$ año de publicación puntual y continua. Durante los trece años que se ha publicado, ha permitido -como publicación científicaproporcionar y conservar un registro permanente de las contribuciones y con ello ha contribuido al progreso de la ciencia. Así mismo, la Revista Biomédica ha sido un medio eficiente de comunicación entre investigadores latinoamericanos y de otros países y ha favorecido a fortalecer la identidad de grupos profesionales dedicados al quehacer científico.

Desde el inicio de su publicación en 1990 a diciembre de 2002, la Revista Biomédica ha publicado en total 1062 colaboraciones, incluyendo artículos arbitrados (revisión por pares), simposios y resúmenes de congresos (cuadro 1). El 70.6\% de las colaboraciones arbitradas han sido de origen local (estado de Yucatán), el 15.6\% de origen nacional y el $13.8 \%$ de países extranjeros (cuadro 1). En la actualidad la Revista Biomédica tiene registrado 973 suscriptores (331 institucionales y 642 personales) cuya distribución se observa en cuadro 1.

Con el inicio del volumen 14 , la política editorial de la revista sufrirá algunos cambios. El principal será que durante este año solamente se aceptarán trabajos relacionados a la medicina humana, para con este enfoque transformar a la Revista Biomédica de una revista de temática biomédica general a una revista de temática de medicina humana en general. Sólo serán aceptados para revisión por pares los artículos de medicina veterinaria que cubran tópicos relacionados con la medicina humana. Los artículos de medicina veterinaria que hayan sido aceptados o que estén en proceso de evaluación y sean aceptados para su publicación, se publicarán durante el año 2003.

Estos cambios son necesarios, ya que en el contexto de la publicación científica, por razones de registro en los índices bibliográficos, así como en la selección de las revistas por parte de los lectores, es recomendable la separación de las publicaciones de medicina humana y de medicina veterinaria. Por otro lado, esta sugerencia ya había sido emitida en una encuesta evaluadora de la Revista Biomédica realizada en el 2000 (1) y ha sido reafirmada por los miembros del Comité Editorial de la revista, así como por las autoridades académicas de la Universidad Autónoma de Yucatán. Estas modificaciones en la política editorial no representan de ninguna manera algún desprecio a la producción científica de la medicina veterinaria, la que orgullosamente representa el $17.8 \%$ de todos los artículos arbitrados y publicados por la Revista Biomédica hasta diciembre de 2002. Nuestro agradecimiento a todos los profesionales del área de la medicina veterinaria por estas contribuciones.

Otro cambio en la estructura editorial de la revista es la incorporación como Editores Asociados del M. en C. Fernando Álvarez-Cervera y del M.C. Carlos Castro-Sansores, lo que permitirá un mayor dinamismo a la labor editorial.

También en este número iniciamos una sección denominada "Contribuciones de la Universidad 


\section{RA Góngora-Biachi.}

Autónoma de Yucatán a la Medicina”. En esta sección se publicarán los logros en el campo de la medicina de los grupos de investigadores de esta universidad. Así mismo se fomenta ya la sección "Foro Hospitalario", que será en sí un espacio para los profesionales de los diferentes hospitales de México y el extranjero, en donde exponga su experiencia en tópicos relevantes de su entorno geográfico (revisiones, casos clínicos inusuales, nuevas experiencias terapéuticas, estudios epidemiológicos).

Para nuestros colaboradores, a partir del año 2003, abrimos la posibilidad de enviar sus trabajos a través de la Internet.

Con estos cambios en la política editorial, la Revista Biomédica reafirma su compromiso de continuar con una evolución positiva $(2,3)$, que siempre se ha traducido en mantener la calidad de su

\section{Cuadro 1 \\ Características bibliométricas de la Revista Biomédica (1990-2002)}

\section{CONCEPTO RESULTADOS}

\begin{tabular}{cc} 
Colaboraciones & \\
Arbitradas & 398 \\
Simposios & 55 \\
Resúmenes de congresos & 609 \\
Origen de los artículos arbitrados $(\mathbf{n}=\mathbf{3 9 8})$ \\
Yucatán México & $281(70.6 \%)$ \\
Nacionales (México) & $63(15.6 \%)$ \\
Extranjeros & $55(13.8 \%)$ \\
Distribución (n= 973 suscripciones): \\
Locales & $346(35.5 \%)$ \\
Nacionales & $552(56.7 \%)$ \\
Extranjeros & $75(7.7 \%)$ \\
\hline
\end{tabular}

contenido que la definan como una revista científica competitiva en el mundo de la comunicación científica.

\section{REFERENCIAS.}

1.- Álvarez-Cervera FJ, Góngora-Alfaro JL, Bata-García JL, Heredia-López FJ. Análisis de la Revista Biomédica en sus primeros diez años. Rev Biomed 2000; 11:235-49.

2.- Góngora-Biachi RA. Análisis de la Revista Biomédica. Rev Biomed 1995; 6:1-4.

3.- Góngora-Biachi RA. La Revista Biomédica: una década de su publicación. Rev Biomed 1999; 10: 197-8.

\section{Revista Biomédica}

